\title{
QbD Enabled Azacitidine Loaded Liposomal Nanoformulation and Its In Vitro Evaluation
}

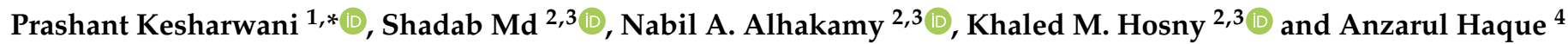 \\ 1 Department of Pharmaceutics, School of Pharmaceutical Education and Research, Jamia Hamdard, \\ New Delhi 110062, India \\ 2 Department of Pharmaceutics, Faculty of Pharmacy, King Abdulaziz University, Jeddah 21589, Saudi Arabia; \\ shaque@kau.edu.sa (S.M.); nalhakamy@kau.edu.sa (N.A.A.); elswaify2000@yahoo.com (K.M.H.) \\ 3 Center of Excellence for Drug Research \& Pharmaceutical Industries, King Abdulaziz University, \\ Jeddah 21589, Saudi Arabia \\ 4 Department of Pharmacognosy, College of Pharmacy, Prince Sattam bin Abdulaziz University, Al-kharj 16278, \\ Saudi Arabia; a.anwarulhaque@psau.edu.sa \\ * Correspondence: prashantdops@gmail.com
}

Citation: Kesharwani, P.; Md, S.; Alhakamy, N.A.; Hosny, K.M.; Haque, A. QbD Enabled Azacitidine Loaded Liposomal Nanoformulation and Its In Vitro Evaluation. Polymers 2021, 13, 250. https://doi.org/10.3390/ polym 13020250

Received: 26 November 2020 Accepted: 29 December 2020 Published: 13 January 2021

Publisher's Note: MDPI stays neutral with regard to jurisdictional clai$\mathrm{ms}$ in published maps and institutional affiliations.

Copyright: $(\odot 2021$ by the authors. Licensee MDPI, Basel, Switzerland. This article is an open access article distributed under the terms and conditions of the Creative Commons Attribution (CC BY) license (https:// creativecommons.org/licenses/by/ $4.0 /)$.

\begin{abstract}
Azacitidine (AZA), an inhibitor of DNA methyltransferase, is a commonly recognized drug used in clinical treatment for myelodysplastic syndrome and breast cancer. Due to higher aqueous solubility and negative log P of AZA causes poor cancer cell permeation and controlled release. The objective of the present study was to formulate and optimize AZA-loaded liposome (AZA-LIPO) for breast cancer chemotherapy by using Box Behnken design (BBD) and in vitro evaluation using MCF-7 cells. AZA-LIPO were prepared using a thin film hydration technique and characterization study was performed by using FTIR and DSC. The prepared formulations were optimized using BBD and the optimized formulation was further subjected for particle size, surface charges, polydispersity index (PDI), drug loading, entrapment efficiency, TEM, XRD, in-vitro drug release and hemolytic toxicity. The mean particle size of optimized AZA-LIPO was $127 \mathrm{~nm}$. Entrapment efficiency and drug loading of AZA-LIPO was found to be $85.2 \% \pm 0.5$ and $6.82 \pm 1.6 \%$, respectively. Further, in vitro drug release study showed preliminary burst release in $2 \mathrm{~h}$ followed by a sustained release for $36 \mathrm{~h}$ in phosphate buffer at different $\mathrm{pH}(4.0,5.5$, and 7.4$)$ as compared to free drug. Drug release was found to be $\mathrm{pH}$ dependent, as the $\mathrm{pH}$ was increased, the drug release rate was found to be low. Time-dependent cell viability assay exhibited significant higher cell viability and higher internalization than free AZA in MCF-7 cells. AZA-LIPO were more effective than the free AZA in reducing $\mathrm{Bcl} 2$ expression, while increasing pro-apoptotic Bax and caspase- 3 activity. The result showed that the formulated biocompatible AZA-LIPO nano-formulations may be used as an efficient anti-cancer drug delivery system for the treatment of breast cancer after establishing preclinical and clinical studies.
\end{abstract}

Keywords: liposomes; box-behnken design; azacitidine; lipid film hydration technique; breast cancer; MCF-7 cell line; chemotherapy

\section{Introduction}

In 1960s Azacitidine (AZA) was primarily synthesized as an analogue of 2 '-deoxycitidine a DNA methyl transferase inhibitor [1,2]. AZA is the most preferred and recommended drug for myelodysplastic syndrome (MDS) and breast cancer treatment [3-5]. However, the clinical limitation of AZA drug is due to the variations in their physicochemical properties such as very high aqueous solubility $(22.67 \mathrm{mg} / \mathrm{mL})$, high metabolism, low half-life (less than $4 \mathrm{~h}$ ), low oral bioavailability and poor stability profile under neutral $\mathrm{pH}$ for 7 days at $4{ }^{\circ} \mathrm{C}$ [6]. Due to high AZA hydrophilicity, which results in a failure of the tailor-made profile and leads to non-specific systemic distribution of AZA along with low drug permeation at the cancer site [7]. Whereas at higher dose it slows down the cell propagation 
by forming covalent linkage with DNA methyltransferase enzyme which inhibit AZA synthesis [8]. Liposomes are the nanocarrier, which are small spherical bilayered lipid vesicles, hence allowing the incorporation of both hydrophilic and lipophilic material in their respective compartments $[9,10]$. Liposomes are promising carriers for delivery of higher drug payloads to target site and prolongs the circulation time in systemic circulation [11,12]. Liposomes have biocompatible and biodegradable properties and most acceptable as drug delivery vehicles. These nanocarriers can move through lipid bilayers of cancer cells with increased AZA concentration at the site of action and eventually increase cytotoxicity $[13,14]$. To the best of the authors' knowledge, to date, AZA-loaded liposomes were not formulated. The advantage of using the formulation of AZA-loaded liposomes is that it will provide easy permeation in cells and further provide controlled release of AZA at the site of cancer. Therefore, AZA-encapsulated liposomes (AZA-LIPO) with an approach for targeting nanoparticles as chemotherapeutic agents using soy lecithin and cholesterol and a thin-film hydration technique was prepared. Soya lecithin and cholesterol are excipients were used for preparation of AZA loaded liposomal formulation. Both soya lecithin and cholesterol are approved by the United States Food and Drug Administration (USFDA) and are enlisted as generally regarded as safe (GRAS) [15]. Quality by design $(\mathrm{QbD})$ approaches were implemented during the development of AZA-LIPO to evaluate the effects of various parameters related to process aspects on product development [16]. $\mathrm{QbD}$ is a risk assessment-based and systematic approach for improving the quality and should be applied during the preliminary stage of formulation optimization, designing and development phase for qualitative uniformity in products. This approach also helps in analyzing the consequences of critical process parameter (CPP) on critical quality attributes (CQA) [17]. The Box Behnken Design (BBD) is implemented to attain the quality target product profile (QTPP) in the minimum number of experimental runs [18]. The effects of major CPP on the CQA \% entrapment efficiency and particle size were studied using BBD [19]. Furthermore, the optimized AZA loaded liposomes were characterized using Fourier transform infrared spectroscopy (FTIR), differential scanning calorimetry, transmission electron microscopy, $\mathrm{x}$-ray diffraction study and in vitro release study. Cellular uptake study, cell viability, Bax, Bcl-2 and caspase activity of optimized AZA loaded liposomes and free AZA were investigated in mcf-7 breast cancer cells.

\section{Materials and Methods}

\subsection{Chemicals}

AZA was procured as a gift sample from Micro Labs Pvt. Ltd. (Bangalore, Karnataka, India). Lecithin, cholesterol and 3-(4, 5-Dimethylthiazol-2-yl)-2, 5-diphenyltetrazolium bromide) (MTT) was purchased from HiMedia laboratories Pvt. Ltd. (Mumbai, India). Chloroform was purchased from Lobachemie Pvt Ltd. (Mumbai (India) and deionized water was purchased from Milli-Q system (Millipore, Bedford, Mumbai, India). Fluorescein isothiocynate (FITC) and 4',6-diamidino-2-phenylindole (DAPI) were purchased from Sigma Aldrich (Mumbai, India). All other solvents and chemicals were of analytical grade and obtained from other local supplier.

\subsection{Preparation Method of AZA Loaded Liposomes}

The AZA encapsulated liposomes (AZA-LIPO) were prepared by lipid thin film hydration technique. The AZA-LIPO comprises of cholesterol (CH) and lecithin (PC) in the ratio of (3:7) Soya $\mathrm{CH} / \mathrm{PC}$ (in given quantity) were dissolved in $100 \mathrm{~mL}$ round bottom flask (RBF) containing $5 \mathrm{~mL}$ chloroform. The organic solvent was evaporated using Rota vapour (IKA RV10) at speed of $65 \mathrm{rpm}$ and temperature of $37^{\circ} \mathrm{C}$ for $10 \mathrm{~min}$ to obtained thin lipid film. Excessive solvents were removed by keeping RBF (Round bottom flask) under vacuum for $24 \mathrm{~h}$. The drug was dissolved in phosphate buffer $\mathrm{pH} 7.4(10 \mathrm{~mL})$ for hydration of lipid thin film slowly for $30 \mathrm{~min}$ until it get completely dissolved [20]. Multilamellar vesicular liposomes formed were probe sonicated for $15 \mathrm{~min}$ at amplitude of $20 \mathrm{~W}$ to obtained unilamellar vesicular liposomal suspension [21]. The liposomal suspension was 
further subjected to freeze drying by using $5 \% w / v$ of mannitol to obtained lyophilized powder and stored at $4{ }^{\circ} \mathrm{C}$ in airtight container for further experiments [22]. Graphical representation for the preparation of AZA loaded liposomes has been represented in the Figure 1.

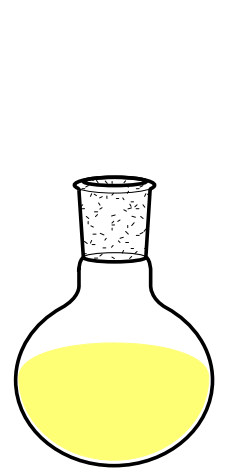

Lipid and other excipient dissolved in organic solvent

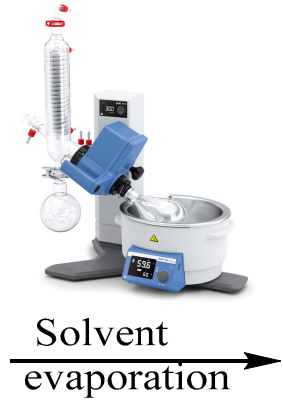

Thin lipid film

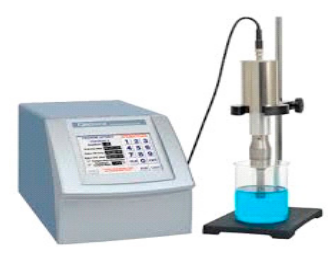

Aqueous solution containing drug
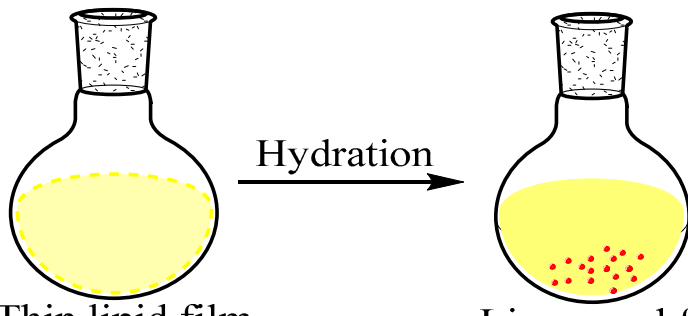

Liposomal formulation containing MLV

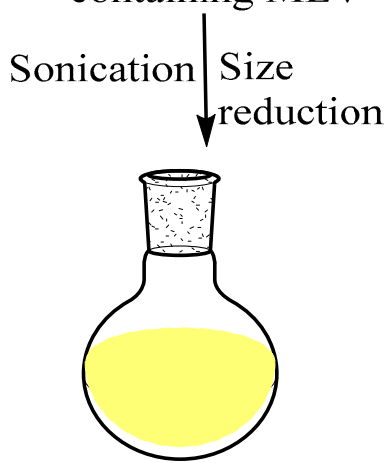

Liposomal suspension

Figure 1. Graphical representation for the preparation of Azacitidine (AZA)-loaded liposomes.

\subsection{Box Behnken Design and Optimization Condition (BBD)}

In this design BBD includes multiple center points with three independent factors and 3 levels with 17 experimental runs were utilized to assemble second order polynomial equation to optimize batch with desirable characteristics [23]. This design was implemented to evaluate simultaneous effect of CPP on responses using Design Expert Software (Version 7.16, Stat-Ease, Inc., Minneapolis, MN, USA). The crucial CPP were $w / v$ lipid concentration $\left(\mathrm{Y}_{1}\right), w / v$ cholesterol concentration $\left(\mathrm{Y}_{2}\right)$ and sonication time $(\mathrm{min})\left(\mathrm{Y}_{3}\right)$ with their respective levels -1 (low), 0 (medium) and +1 (high) whereas the CQA were particle size (nm) and $3 \%$ drug entrapment efficiency (\%) as shown in Table 1 . The quadratic equations obtained from BBD is as follows:

$$
X=B_{0}+B_{1} Y_{1}+B_{2} Y_{2}+B_{3} Y_{3}+B_{12} Y_{1} Y_{2}+B_{13} Y_{1} Y_{3}+B_{23} Y_{2} Y_{3}+B_{11} Y_{1}^{2}+B_{22} Y_{2}^{2}+B_{33} Y_{3}^{2}
$$

where, $\mathrm{X}$ is CQA (responses), $\mathrm{B}_{0}$ is denoted as intercept, $\mathrm{B}_{1}$ to $\mathrm{B}_{33}$ in equation is regression coefficients of given factors and $Y_{1}$ to $Y_{3}$ are the code given to independent factors. Considerable effect of each independent variable with their respective levels towards the dependent variable were predicted via analysis of variance (ANOVA) and $p$ value < 0.05 [24]. The check points were evaluated by batch T1 and T2 to predict the independent factor on responses of desired batch. The response surface model was generated to observe the effect of CQA on AZA-LIPO particle size and \% EE. 
Table 1. Independent variables with their responses and limits.

\begin{tabular}{cccc}
\hline Actual Coded Value & A & B & C \\
\hline-1 & 70 & 10 & 10 \\
0 & 80 & 20 & 15 \\
1 & 90 & 30 & 20 \\
$Y_{1}$ & & Lipid Concentration $(\% w / v)$ & \\
$Y_{2}$ & & Cholesterol concentration $(\% w / v)$ \\
$Y_{3}$ & Sonication Time (min) \\
Dependent variables & Particle size (nm) and entrapment efficiency (\%) \\
\hline
\end{tabular}

\subsection{Particle Size, PDI and Zeta Potential}

The particle size, polydispersity index (PDI), and zeta potential were determined using Quasi elastic light scattering techniques. AZA-loaded liposomal suspension was diluted with 1:100 distilled water and analyzed by means Nano-ZS zetasizer (Malvern instruments, Malvern, UK) [25-27].

\subsection{Drug Entrapment and Drug Loading Efficiency}

The drug content of AZA - LIPO was estimated by high speed centrifugation method. Prepared AZA-LIPO suspensions $(1 \mathrm{~mL})$ were subjected for centrifugation on laboratory centrifuge (sigma 2-16PK Labmate (Asia) Pvt. Ltd.) at 12,000 rpm for the time period of $40 \mathrm{~min}$ [28]. The supernatant was taken and preceded for further analysis in UV-VIS spectrophotometer (LABINDIA UV 3000) at the wavelength of $242 \mathrm{~nm}$ for the analysis of un-entrapped AZA in the liposomal formulation and the percent drug entrapment efficiency was calculated [29]. The percentage Drug loading (\%DL) was calculated from the pellet part of centrifuged AZA-LIPO suspension.

$$
\begin{aligned}
& \% \mathrm{EE}=\frac{\text { amount of AZA added in liposome }- \text { amount of unentrapped AZA }}{\text { amount of AZA added in liposome }} \times 100 \\
& \% \mathrm{DL}=\frac{\text { amount of AZA added in liposome }- \text { amount of unentrappedAZA }}{\text { total amount of liposomal formulation (drug }+ \text { excipients) }} \times 100
\end{aligned}
$$

\subsection{Fourier Transform Infrared Spectroscopy (FTIR)}

AZA, Lyophilized AZA -LIPO and physical mixtures of excipients (Cholesterol, soy lecithin, mannitol) samples were examined under FTIR spectrophotometer. The sample was converted into $\mathrm{KBr}$ pellets using a hydraulic press. Then, pellets were exposed to infrared radiation to pass through samples $[30,31]$. The spectrums were recorded in the region of 4000 to $400 \mathrm{~cm}^{-1}$.

\subsection{Differential Scanning Calorimetry (DSC)}

Thermo analytical study was performed by a DSC instrument (TA Instrument Trios v4 2.13662 software) to determine the physical state of the drug, mannitol and lyophilized AZA-LIPO. The study was conceded at the temperature range between 50 and $250^{\circ} \mathrm{C}$ at a scanning rate of $10^{\circ} \mathrm{C} \mathrm{min}^{-1}$. The samples for analysis were prepared by weighing accurate quantity of Drug (AZA), mannitol and AZA-LIPO formulation in aluminum pan and then crimped with lid. The crimped pan containing sample was kept in DSC instruments with reference blank pan at the back to analyze the sample [32]. DSC thermogram of samples (AZA, mannitol and AZA-LIPO formulation) was recorded [33].

\subsection{X-Ray Diffraction Study}

The samples were analyzed on by X-ray powder diffractometer (XRD-2000, Rigaku, Tokyo, Japan) by using $\mathrm{Cu}-\mathrm{K} \alpha$ radiation set with nickel filter at 1.5404 angstrom in order to evaluate the X-ray powder diffraction pattern of pure AZA, excipients and AZA-LIPO 
lyophilized powder. The samples were putted down on a glass sample holder and the diffraction patterns were recorded $[34,35]$.

\subsection{Transmission Electron Microscopy (TEM)}

AZA-LIPO morphology were imaged on TEM. The liposomes were stained with $2 \%$ uranyl acetate, formulation is placed on carbon coated grids of 400 mesh and kept on room temperature for $60 \mathrm{sec}$. Liposomes were observed under the microscope with accelerating voltage of $60-100 \mathrm{kV}[36,37]$.

\subsection{In-Vitro Drug Release Study}

The in vitro release study of free AZA $(5 \mathrm{mg})$ and dose equivalent to AZA liposomal suspension was performed at Phosphate buffer saline (PBS) at different $\mathrm{pH}(4.0,5.5$, and 7.4). Free AZA nanosuspension was prepared by dissolving the $5 \mathrm{mg}$ of AZA (amount of AZA added in formulation per $\mathrm{mL}$ ) in $1 \mathrm{~mL}$ of PBS (pH 7.4) followed by sonication [38]. The drug release experiment was carried out in dialysis bag (nitrocellulose membrane, Mol. Wt. cut off $12,000 \mathrm{Da}$ ). Dialysis bag was activated by treatment with phosphate buffer solution half an hour prior to release study. Equivalent amount of free drug nanosuspension and AZA-LIPO nanosuspension were placed in nitrocellulose bags and the ends of bag were sealed by tie thread. PBS at different $\mathrm{pH}(4.0,5.5$, and 7.4) is used as dissolution medium for release study $[39,40]$. The nitrocellulose bags containing formulation were kept in $100 \mathrm{~mL}$ of dissolution medium at $37^{\circ} \mathrm{C}$ at $100 \mathrm{rpm}$ over a magnetic stirrer for $24 \mathrm{~h}$. Samples were withdrawn at different time intervals and the sink condition was maintained by replenishing the equal amount of PBS. The absorbance was taken on a UV-Visible spectrophotometer at $243 \mathrm{~nm}$. A drug release study was conducted in triplicates and the drug release kinetic model was applied to obtained release data.

\subsection{Hemolytic Toxicity}

Hemolytic toxicity was examined by hemoglobin content in the supernatant of the centrifuged RBC suspension spectrophotometrically followed by our previously reported method [31,40-43]. RBCs were collected from whole human blood by centrifugation, followed by RBCs washing with normal saline to obtain a clear colorless supernatant. Cells were suspended in normal saline and developed formulations were added at different concentration and tubes could stand for half an hour with gentle intermittent shaking and were centrifuged for $15 \mathrm{~min}$ at $3000 \mathrm{rpm}$. The supernatants were pooled, and spectrophotometric analysis was done at $540 \mathrm{~nm}$ to determine the degree of hemolysis.

\subsection{Cytotoxicity Assay}

The cytotoxicity assay of Free AZA, blank liposome and AZA-LIPO on MCF-7 breast cancer cells were done by MTT 3-(4,5-dimethylthiazol-2-yl)- 2,5-diphenyltetrazolium assay. In a 96 well microtiter plate MCF-7 cells $\left(2 \times 10^{4} /\right.$ well $)$ were seeded and left to attach for $24 \mathrm{~h}$. Fresh prepared media was added and the cells were treated different concentrations of free AZA, blank liposome and AZA-LIPO (5, 10 and $15 \mu \mathrm{M}$ AZA/well) culture medium treated group is considered as control, incubated at $37^{\circ} \mathrm{C}$ for $24 \mathrm{~h}$ in $\mathrm{CO}_{2}$ incubator [44]. The cells were rinsed with PBS 7.4 and treated with MTT reagent $(5 \mathrm{mg} / \mathrm{mL})$ and subjected to incubate for $4 \mathrm{~h}[45,46]$. The formazan crystals were dissolve via adding $100 \mu \mathrm{L}$ of DMSO in a 96 well plate the generated by living cells. Then the absorbance was observed by microplate reader at a same excitation and emission wavelength of $570 \mathrm{~nm}$. PBS-treated cells function as controls for the formulation-treated cells, and considered to be $100 \%$ viable [47]. Data were shown as a mean \pm standard deviation (SD), and the extent of cytotoxicity was observed for 24 and $48 \mathrm{~h}$ after treatment.

$$
\% \text { Cell viability }=\frac{(\text { Absorbance treatment })}{(\text { Control absorbance })} * 100
$$




\subsection{Confocal Microscopy}

To evaluate the cell internalization efficiency of AZA-LIPO in MCF-7 cells confocal microscopy studies were conducted. MCF-7 cells were incubated at a density of $1 \times 10^{3}$ cells in six well poly-l-lysine coated plate and incubated for $24 \mathrm{~h}$. After incubation cells are treated with FITC loaded Liposomes (FITC-LIPO $(20 \mu \mathrm{L})$ and incubated for $4 \mathrm{~h}$. Further, cells were treated with DAPI and incubated for $15 \mathrm{~min}$. Cell uptake images were taken by a Confocal Laser Scanning Microscope [45,48].

\subsection{Determination of Bax, Bcl-2 and Caspase-3 Proteins Expression}

Analysis of Bax, Bcl-2 and caspase-3 protein was performed using the ELISA method. The MCF-7 cells $\left(2 \times 10^{4} /\right.$ well $)$ were seeded into 96-well plate. The cells were treated with free AZA, AZA-LPO and blank liposome samples for $24 \mathrm{~h}$. Thereafter, the wells were incubated with monoclonal antibodies against Bax (Ab-1) (DRG ${ }^{\circledR}$ Human Bax ELISA Kit), Bcl-2 (Zymed ${ }^{\circledR}$ Bcl-2 ELISA Kit) and caspase-3 (Invitrogen ELISA kit). The procedure was followed as per manufacturer instruction [49].

\subsection{Statistical Analysis}

The experimental design and statistical calculations were analyzed in design expert software. In BBD 17 runs with 3 center points were implemented to validate polynomial equation by ANOVA (Analysis of variance).

\section{Result and Discussion}

\subsection{Preparation of AZA-LIPO}

The lipid thin film hydration method was used to load the AZA a hydrophilic drug into the liposome. Liposomal formulation can entrap the hydrophilic drugs in the outer layer of vesicle. Formulated liposomal nanosuspensions were sonicated and at last liposomes were freeze-dried and stored at $4{ }^{\circ} \mathrm{C}$ using $5 \% w / v$ mannitol as a cryoprotectant.

\subsection{Optimization of AZA-LIPO}

The lipid film hydration technique is a widely preferred method for the preparation of liposomes, even though it requires optimization for process parameters with preferred particle size and \% entrapment efficiency. Process parameters such as lipid weight concentration (mg), cholesterol weight concentration (mg) and sonication time (min) affect the liposome characteristics. Some other parameters such as rota vapor speed (rpm), film hydration time (min) also showed effect on liposome characteristics. Effects of various independent variables on responses were shown in Table 2.

The parameters for liposome selection were set with low particle size $(100-250 \mathrm{~nm})$ and higher entrapment efficiency as needed. The liposome formulation with its expected data from DOE software and the observed data from experimental data were found to be closer. Two check points T1 and T2 were utilized for the validation of actual and predicted values as shown in Table 3 . The $p<0.05$ values of responses such as \% EE and particle size were found to be significant. 
Table 2. Effect of independent variable on various responses expressed as mean \pm SD $(n=3)$.

\begin{tabular}{cccccc}
\hline Run & $\mathbf{Y}_{\mathbf{1}}$ & $\mathbf{Y}_{\mathbf{2}}$ & $\mathbf{Y}_{\mathbf{3}}$ & Particle Size $(\mathbf{n m}) \pm \mathbf{S D}$ & Entrapment Efficiency $(\% \mathbf{E E}) \pm \mathbf{S D}$ \\
\hline 1 & 80 & 20 & 15 & $190 \pm 2.12$ & $69.8 \pm 2.24$ \\
2 & 80 & 10 & 20 & $106 \pm 3.23$ & $76.7 \pm 1.31$ \\
3 & 80 & 10 & 10 & $220 \pm 4.11$ & $65.1 \pm 3.22$ \\
4 & 80 & 20 & 15 & $190 \pm 1.14$ & $70.5 \pm 2.03$ \\
5 & 70 & 10 & 15 & $109 \pm 2.02$ & $83.1 \pm 0.52$ \\
6 & 80 & 30 & 20 & $202 \pm 5.17$ & $66.2 \pm 2.14$ \\
7 & 70 & 20 & 20 & $116 \pm 2.24$ & $76.2 \pm 1.02$ \\
8 & 80 & 20 & 15 & $190 \pm 1.45$ & $71.3 \pm 4.01$ \\
9 & 90 & 10 & 15 & $111 \pm 3.26$ & $60.3 \pm 3.36$ \\
10 & 90 & 20 & 10 & $175 \pm 4.02$ & $56.3 \pm 2.13$ \\
11 & 90 & 30 & 15 & $119 \pm 2.31$ & $62.4 \pm 5.24$ \\
12 & 70 & 20 & 10 & $168 \pm 5.12$ & $74.8 \pm 1.18$ \\
13 & 80 & 20 & 15 & $190 \pm 6.31$ & $72.8 \pm 0.53$ \\
14 & 90 & 20 & 20 & $104 \pm 8.01$ & $69.7 \pm 4.12$ \\
15 & 70 & 30 & 15 & $107 \pm 1.17$ & $85.2 \pm 0.51$ \\
16 & 80 & 20 & 15 & $192 \pm 2.38$ & $73.1 \pm 2.18$ \\
17 & 80 & 30 & 10 & $235 \pm 3.54$ & $80.45 \pm 2.46$ \\
T1 & 70 & 30 & 13 & $115 \pm 1.41$ & $79 \pm 1.13$ \\
T2 & 70 & 20 & 10 & $124 \pm 2.84$ & \\
\hline
\end{tabular}

Table 3. Evaluation of design checks point for T1 and T2.

\begin{tabular}{|c|c|c|c|c|}
\hline \multirow{2}{*}{ Response } & & \multicolumn{3}{|c|}{ Runs } \\
\hline & & T1 & T2 & $\begin{array}{l}\text { Optimized } \\
\text { Formulation }\end{array}$ \\
\hline \multirow{3}{*}{ Particle size (nm) } & Observed & 115 & 124 & 107 \\
\hline & Predicted & 130 & 145 & 110 \\
\hline & Residuals & 7 & 8 & -4.82 \\
\hline \multirow{2}{*}{$\mathrm{EE}(\%)$} & Observed & 80.45 & 79 & 85.2 \\
\hline & Predicted & 75.2 & 72.8 & 81.32 \\
\hline
\end{tabular}

\subsection{Particle Size}

The AZA-LIPO film was formed by dissolved drug hydrating the thin film of lipid organic phase containing lipid and cholesterol. The addition of cholesterol stabilizes the phospholipid bilayer of lecithin, while simultaneously reducing the size of multilamellar vesicles by probe sonication to obtain unilamellar vesicular liposome. The change of multilamellar to unilamellar vesicles significantly affects particle size and PDI of liposomal formulation. Mean particle size ranges from 104 to $235 \mathrm{~nm}$ and was prejudiced by lecithin concentration, cholesterol concentration and sonication time. The response surface plots were calculated by using polynomial regression equation.

$$
\begin{gathered}
\text { Particle size }=190.40+1.13 \mathrm{~A}+14.63 \mathrm{~B}-33.75 \mathrm{C}+2.50 \mathrm{AB}-4.75 \mathrm{AC}+20.25 \mathrm{BC}- \\
64.45 \mathrm{~A}^{2}-14.45 \mathrm{~B}^{2}+14.80 \mathrm{C}^{2}
\end{gathered}
$$

The correlation coefficient $\left(R^{2}\right)$ and adjusted $R^{2}$ values for particle size was analyzed to be 0.95 and 0.89 . The particle size of AZA-LIPO increases with increase in concentration of lecithin and sonication time with higher cholesterol shows inverse relationship. The response surface plot for particle size is shown in Figure 2. The lack of fit value $p>0.005$ was found to be significant in the ANOVA model for particle size. Liposome with particle size $<200 \mathrm{~nm}$ are efficient to pass the cell membrane and to release the drug in cytoplasm. 


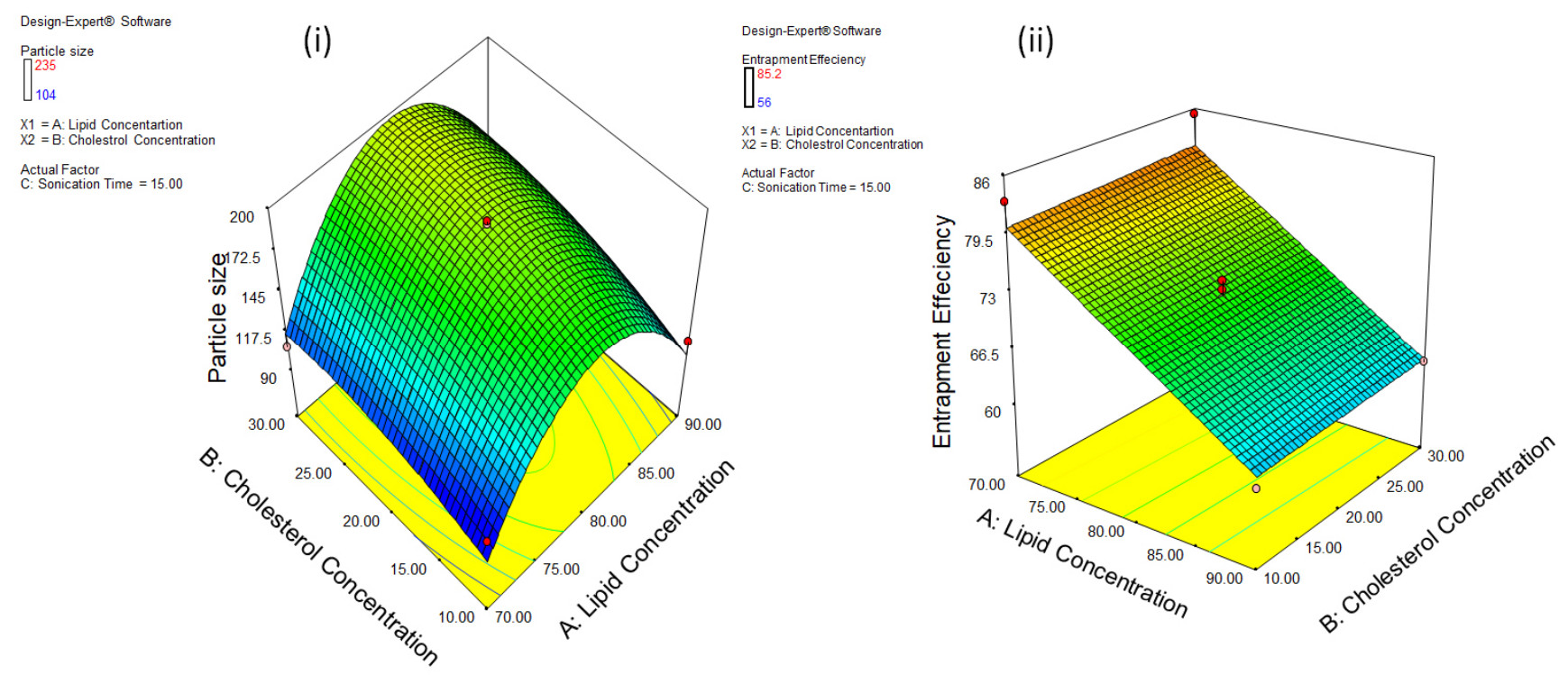

Figure 2. (i) Response surface plot and (ii) contour plot for particle size and entrapment efficiency.

\subsection{Entrapment Efficiency}

Factors which effect the entrapment efficiency which is important for the encapsulation of hydrophilic drug into liposomal formulation. The design applied was found significant ( $p>0.0004)$ and the values for correlation coefficient $R^{2}$ and adjusted $R^{2}$ was found to be 0.88 and 0.80 . The percentage entrapment efficiency of AZA-LIPO was found to be in the range $56 \%$ to $85 \%$. The polynomial equation obtained by design for percent entrapment efficiency is as follows:

$$
\% \mathrm{EE}=71.14-8.82 \mathrm{~A}+0.56 \mathrm{~B}+2.09 \mathrm{C}+0.001 \mathrm{AB}+3.00 \mathrm{AC}-5.33 \mathrm{BC}
$$

The polynomial equation showed that lipid concentration and sonication time are the primary parameters that affects entrapment efficiency. Lipid concentration and sonication time is directly proportional to \% entrapment efficiency. The response surface plot for entrapment efficiency is shown in Figure 2. The lack of fit value was found to be significant in the ANOVA model for \% EE indicating that the regression equation was well fitted. Hydrophilic cavity between bilayers of liposome enhances the encapsulation capacity of hydrophilic drugs. We also found that with the increase in particles size of formulations, the drug loading and entrapment efficiency has also been increased at certain points; after that, increase in particle size leads to decrease in drug loading and entrapment efficiency due to less soluble formulation. This has not always happened, there are various factors that can affect particle size, entrapment and loading together and individually. Our results are well in accordance with the previous studies [27].

\subsection{Data Optimization and Model Validation}

The design expert software 7.0 generates over lay plot contain two regions shown in the yellow and gray region. The yellow region showed a design feasible area and the gray region indicates that the particular region is not suitable to get an optimized batch. The desirability and overlay plot were based on optimized process attributes such as lipid concentration $73.84 \mathrm{mg}$, cholesterol concentration $12.77 \mathrm{mg}$ and sonication time $20 \mathrm{~min}$. The predicted values for responses such as particle size $117.58 \mathrm{~nm}$ and entrapment efficiency $80.25 \%$ were obtained from overlay plot and the desirability criteria for this model is 0.978 as shown in Figure 3. The particle size, PDI and zeta potential of optimized batch 7:3:1 of AZA-LIPO was found to be $107 \pm 1.1 \mathrm{~nm}$ (Figure $4 \mathrm{~A}$ ), $0.035 \pm 0.5$ and $-25 \mathrm{mV}$ respectively 
(Figure 4B) indicates high storage stability of liposome. The \% EE and \%DL of optimized batch was found to be $85.2 \pm 0.5 \%$ and $5.82 \pm 2 \%$ as shown in Table 4 .
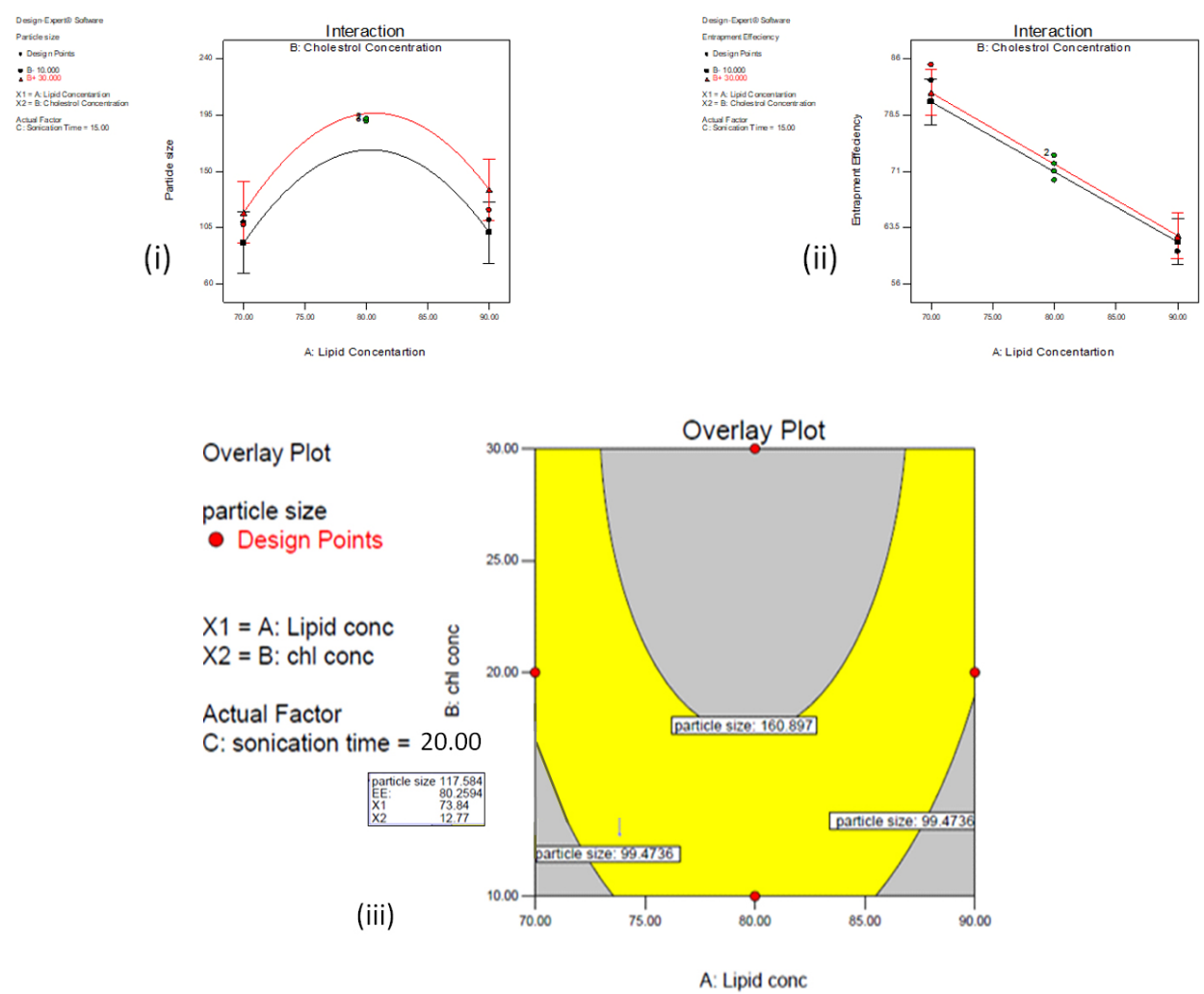

Figure 3. Interaction plot for (i) particle size, (ii) entrapment efficiency and (iii) overlay plot.

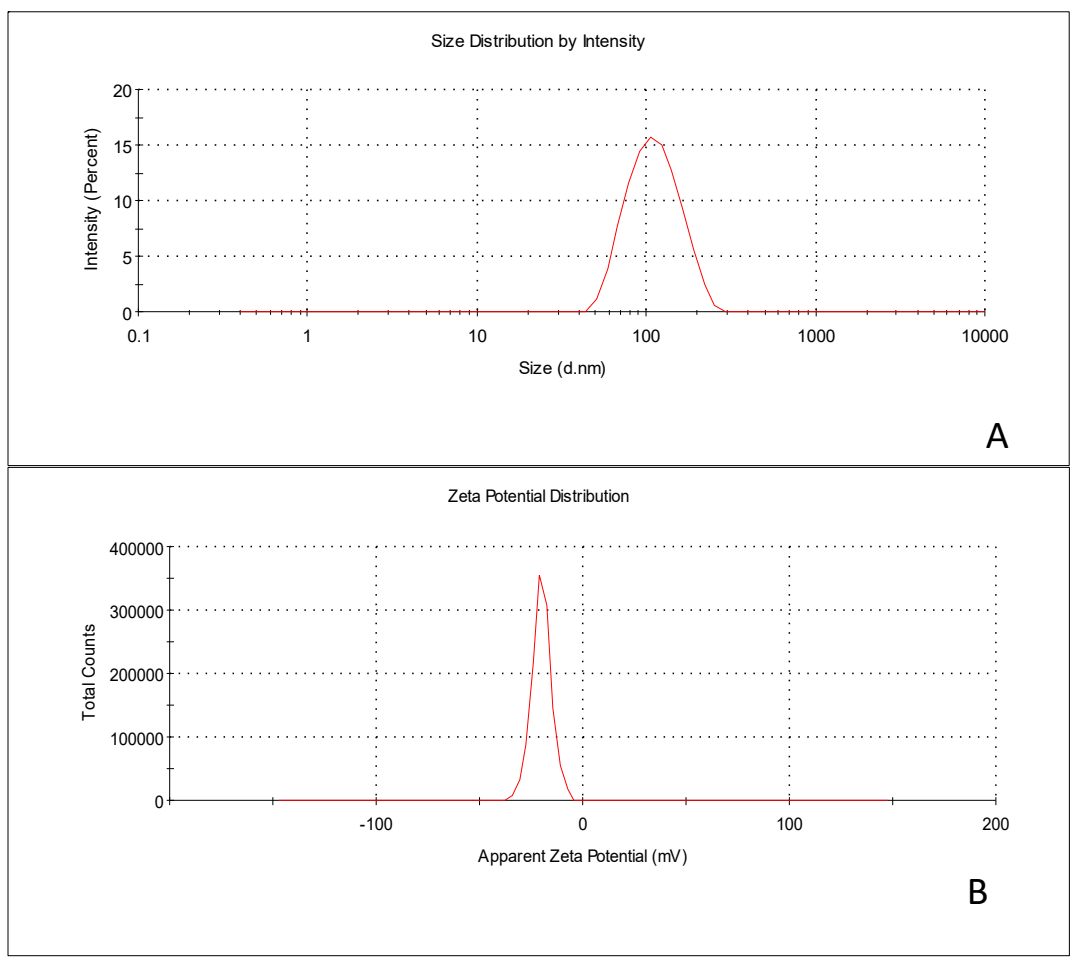

Figure 4. (A) Particle size distribution and (B) zeta Potential of AZA-LIPO formulation. 
Table 4. Drug entrapment efficiency and drug loading of optimized batch.

\begin{tabular}{cccccc}
\hline Batch No. & $\begin{array}{c}\text { Excipients } \\
\text { Drug Ratio }\end{array}$ & Particle Size (nm) \pm SD & PDI \pm SD & $\begin{array}{c}\text { \%Entrapment } \\
\text { Efficiency } \pm \text { SD }\end{array}$ & \%Drug Loading \pm SD \\
\hline B1 & $60: 40: 10$ & $119 \pm 5$ & $0.07 \pm 0.004$ & $60.3 \% \pm 2 \%$ & $5.48 \% \pm 1 \%$ \\
B2 & $70: 30: 10$ & $107 \pm 3$ & $0.035 \pm 0.002$ & $85.2 \% \pm 1 \%$ & $5.82 \% \pm 2 \%$ \\
B3 & $75: 25: 10$ & $109 \pm 6$ & $0.082 \pm 0.005$ & $43.2 \% \pm 3 \%$ & $3.92 \% \pm 4 \%$ \\
B4 & $85: 15: 10$ & $190 \pm 8$ & $0.163 \pm 0.004$ & $29 \% \pm 4 \%$ & $2.64 \% \pm 3 \%$ \\
B5 & $90: 10: 10$ & $111 \pm 2$ & $0.049 \pm 0.003$ & $60 \% \pm 1 \%$ & $5.45 \% \pm 1 \%$ \\
\hline
\end{tabular}

\subsection{FTIR}

The FTIR spectra of AZA, excipients and AZA-LIPO were analyzed as shown in Figure 5. FTIR spectra of AZA show a characteristic peak at $1528.5 \mathrm{~cm}^{-1}$ which indicates the presence of amine group $(\mathrm{N}-\mathrm{H})$ and a sharp peak at $2351.1 \mathrm{~cm}^{-1}$ clears the presence of OH group. The FTIR spectra of excipients (lecithin + cholesterol) exhibit characteristics peak at $1402.1 \mathrm{~cm}^{-1}$ and $1694.91 \mathrm{~cm}^{-1}$. However, the lyophilized AZA-LIPO formulation exhibit smooth spectra with single characteristics sharp peak at $1636.81 \mathrm{~cm}^{-1}$ which indicates that the drug is incorporated into the formulation and no interactions were taking place between drugs and lipids. The lyophilized formulation showed that most of the peaks have vanished, it suggests that certain physical interactions such as formation of hydrogen bonds have occurred between functional groups present in drugs and lipids, but no chemical interactions occur [40].

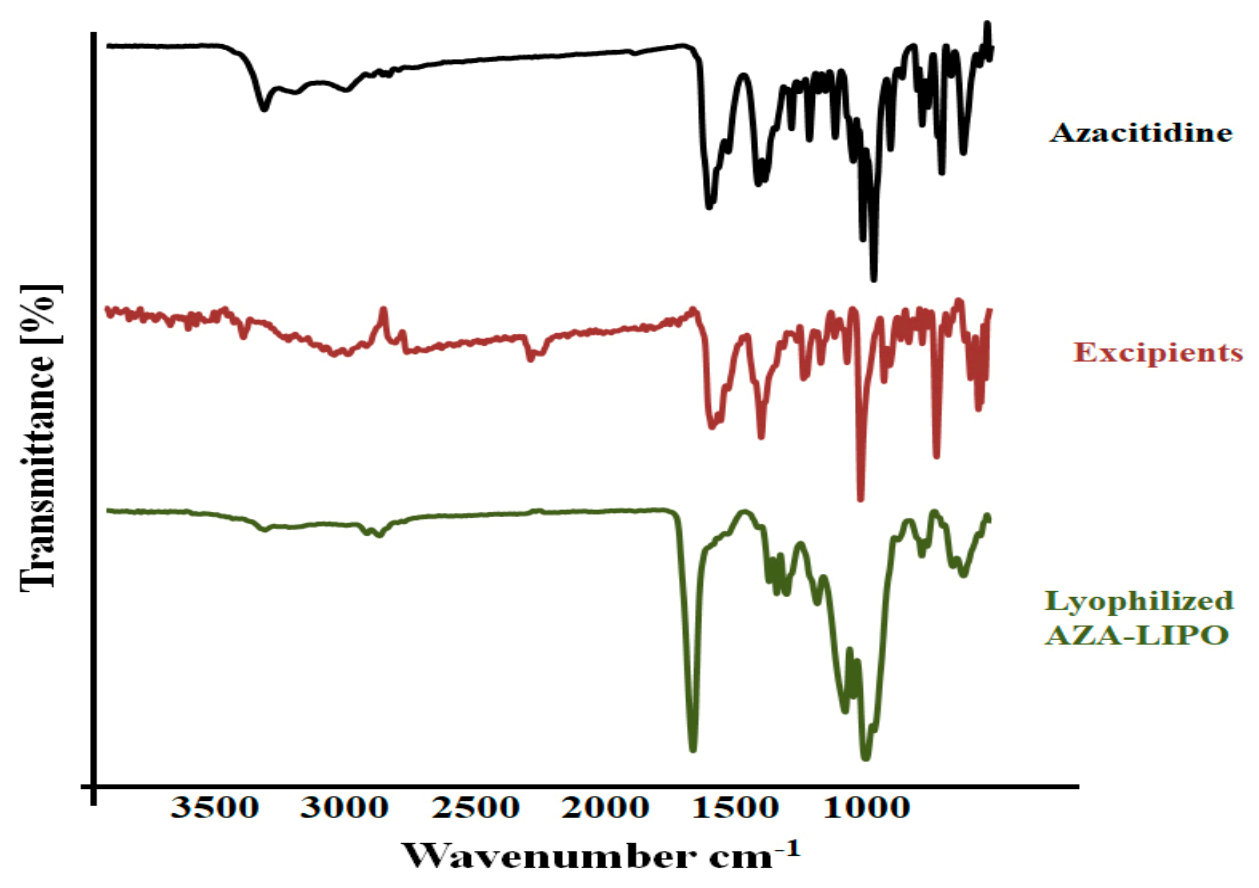

Figure 5. FTIR spectra of AZA, excipients and AZA-LIPO formulation.

\subsection{DSC}

DSC thermogram of AZA, physical mixture (lecithin + cholesterol+ AZA+ mannitol) and AZA-LIPO were shown in Figure 6. AZA exhibits a sharp endothermic peak at $208.3^{\circ} \mathrm{C}$ which represents the crystalline nature of drugs. The DSC mannitol endothermic thermogram was found at $160^{\circ} \mathrm{C}$. However, the DSC endothermic thermogram for AZALIPO showed a diminished peak, which represented complete entrapment of AZA in liposome and conversion of crystalline to an amorphous form. 


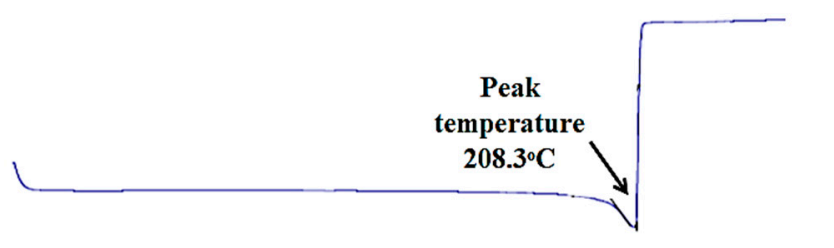

Azacitidine

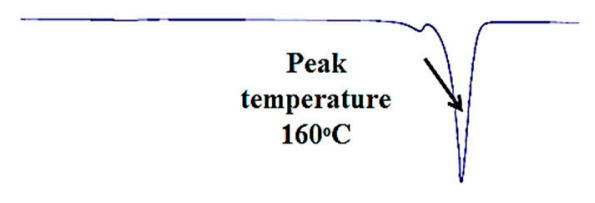

Mannitol
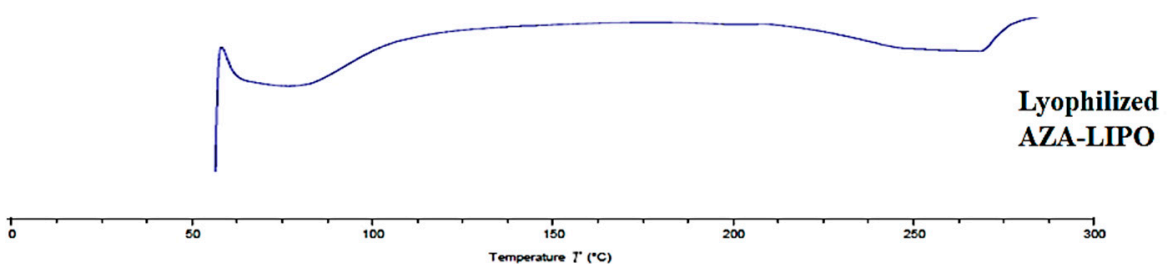

Figure 6. Comparative DSC thermo gram of AZA, excipients and AZA-LIPO formulation.

\subsection{X-Ray Diffraction Study}

X-ray diffraction study of pure AZA, excipients (Soya lecithin, cholesterol and mannitol) and AZA-LIPO were shown in Figure 7. XRD data show a sharp peak for pure AZA which indicates the crystalline nature of drug; whereas, sharp peaks were also observed in case of excipients. AZA-LIPO showed broad peaks, and sharp diffraction peaks were not observed. This may be due to the entrapment of AZA in liposomes. Some sharp peaks appeared in AZA-LIPO formulation could be due to presence of mannitol in formulation.
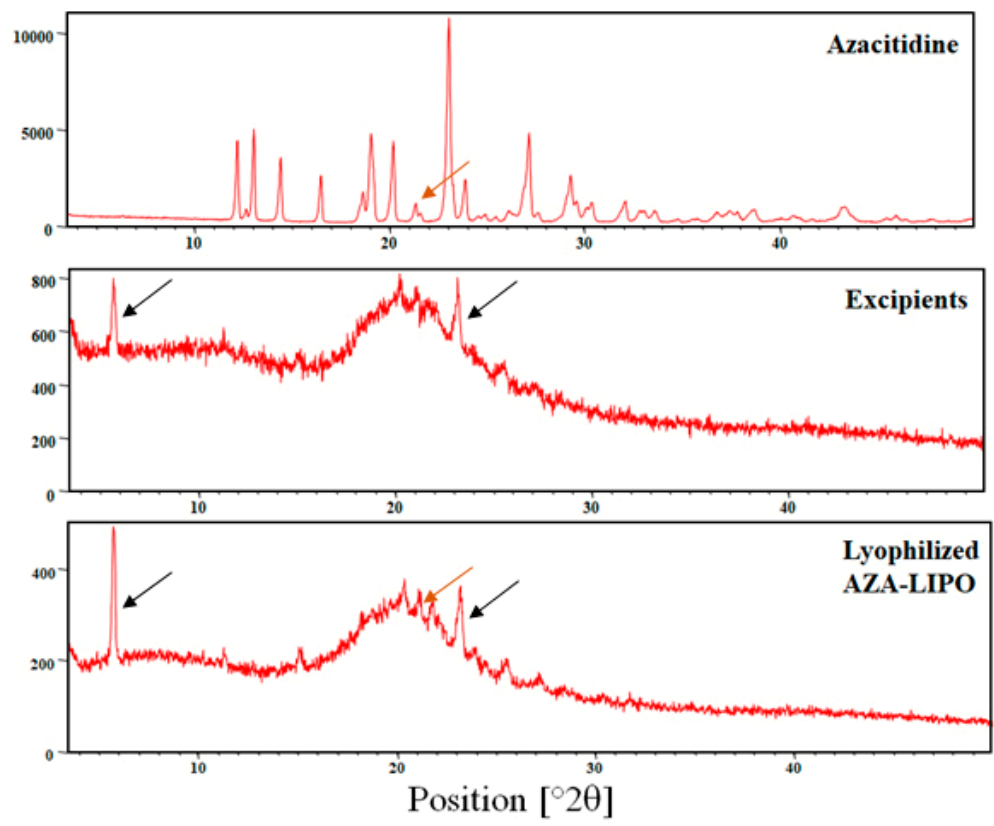

Figure 7. XRD of AZA, excipients and AZA-LIPO formulation.

\subsection{TEM}

TEM images of AZA-LIPO show smooth spherical vesicles. TEM imaged the liposome internal morphology and displayed particle size in a nanometre range (Figure 8A). 
Liposome size was less than $200 \mathrm{~nm}$ suitable for enhanced permeation and retention effect. The zetasizer data confirmed that polydispersity index (PDI) is in the range 0.1-0.2 which showed homogenous size distribution which is good for tumor targeting.
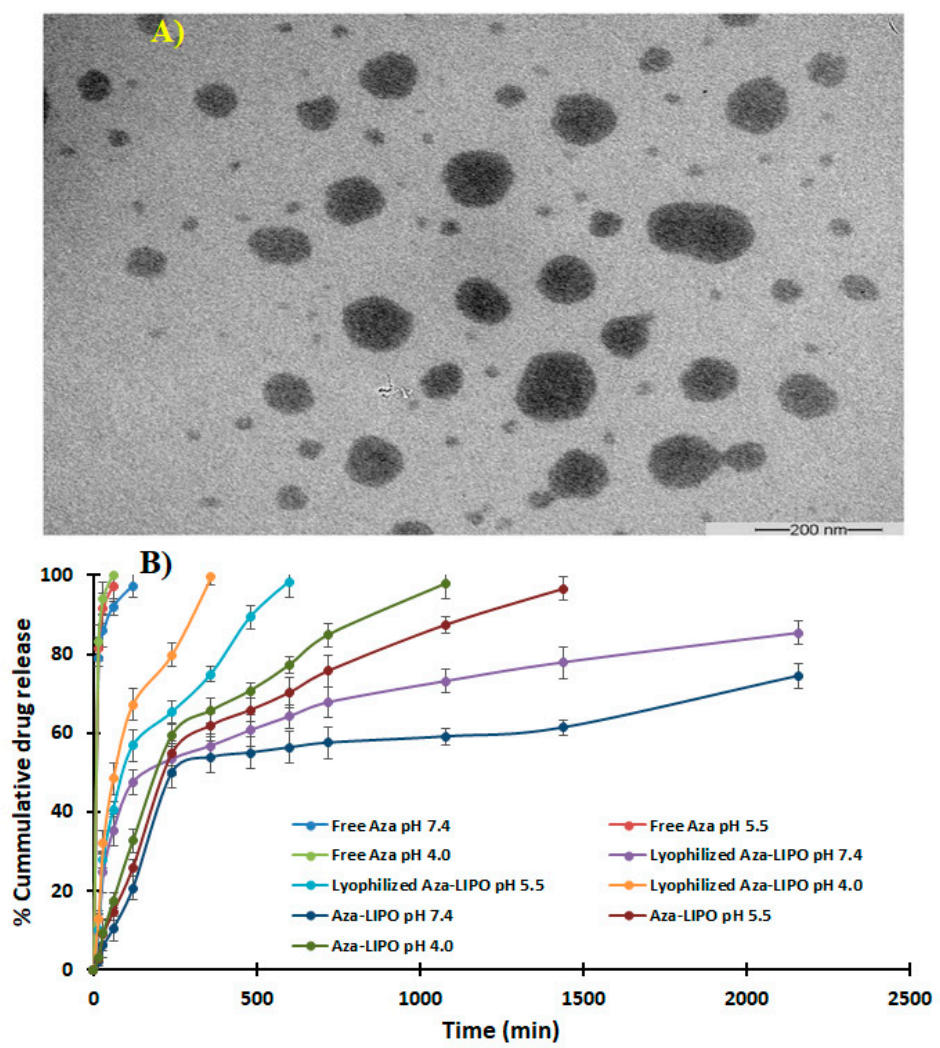

Figure 8. (A) TEM image of AZA-LIPO formulation; (B) in vitro drug release profile of developed formulations $(n=6)$.

\subsection{In Vitro Drug Release Study}

The release study of free AZA $5 \mathrm{mg} / \mathrm{mL}$ and equal amount of AZA-LIPO nano suspension and lyophilized AZA-LIPO liposomes was performed at different $\mathrm{pH}$ (4.0, 5.5, and 7.4) to calculate the release rate of drug as shown in Figure 8B. For free AZA dissolved in water, it was observed that more than $90 \%$ drug release was taken place within $2 \mathrm{~h}(91.97$ $\pm 2.2 \%$ at $\mathrm{pH} 7.4,97.23 \pm 4.3 \%$ at $\mathrm{pH} 5.5$ and $99.98 \pm 3.1 \%$ at $\mathrm{pH} 4.0)$. However, lyophilized AZA-LIPO showed a sustained drug release pattern at all the experimental pHs. The AZALIPO exhibited only $74 \pm 2.3 \%$ of drug release in comparison to lyophilized formulation at $\mathrm{pH}$ 7.4. Higher release of AZA in freeze-dried formulation was observed due to conversion of the drug into amorphous form. However, AZA is hydrophilic in nature, and the release of drug release was prolonged to $36 \mathrm{~h}$ due to liposomal formulation. Drug release was found to be $\mathrm{pH}$ dependent, and drug release was comparatively faster at low tumor $\mathrm{pH}$ ( $\mathrm{pH} 4.0)$ which is advantageous for us as an anticancer candidate. As the $\mathrm{pH}$ was increased, the drug release rate was found to be low. Our results are well in accordance with the previous studies [31,37,41,50-54]. The drug release obtained from AZA-LIPO followed a mixed order release due to burst release initially followed by sustained release pattern for freeze dried formulation, which prolonged the release of drug from liposome bilayers.

\subsection{Hemolytic Toxicity}

The hemolytic toxicity was estimated in terms of percent RBC hemolysis. At highest experimental concentration (0.5\%) it was observed that free drug Aza exhibited 16.74 $\pm 2.48 \%$, while blank liposomes and Aza-Lipo showed $2.86 \pm 0.34 \%$ and $3.16 \pm 1.32 \%$ RBC hemolysis, respectively. Liposome-based formulation significantly decreased RBC 
hemolysis due to Aza's shielding/locking within the liposome. Our observations clearly confirmed the biocompatibility of formed liposome formulations and may be useful in future as a promising drug delivery alternative (Figure 9A).

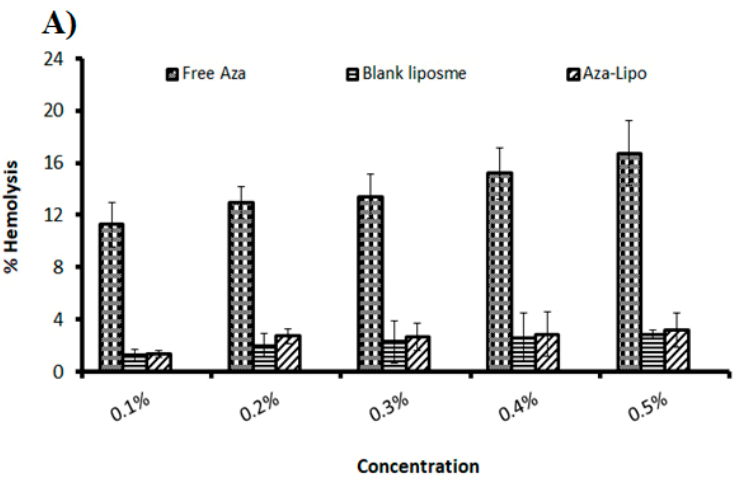

C)

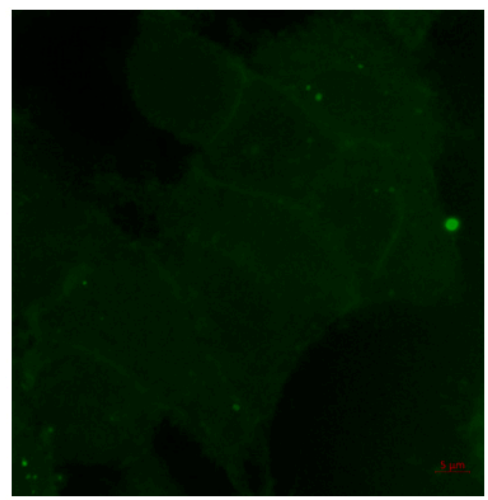

B)

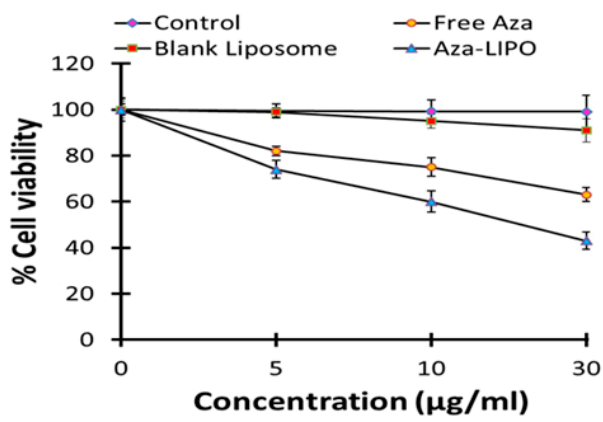

Merged
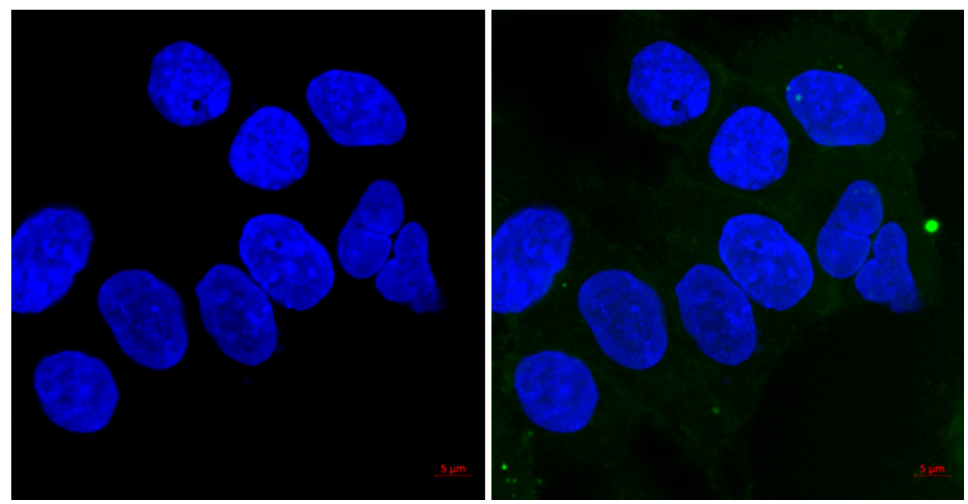

Figure 9. (A) Hemolysis toxicity profile $(n=6),($ B $)$ cytotoxicity assay $(n=6)$ and $(C)$ confocal microscopy of the developed formulations.

\subsection{Cytotoxicity Assay}

An MTT assay was performed to determine in vitro cytotoxicity potential of free AZA, blank liposome and AZA- LIPO. The inhibitory concentration value of AZA and AZALIPO on MCF-7 cell line was found to be $39.54 \mu \mathrm{M}$ and $23.23 \mu \mathrm{M}$ respectively (Figure 9B). Free AZA and formulations were showing a dose-dependent reduction of cell viability on MCF-7 cell line. The blank liposome showed lowest cytotoxicity at highest drug equivalent concentration of $30 \mu \mathrm{M}$. The viability of cells treated with AZA-LIPO $30 \mu \mathrm{M}$ concentration found to be $43 \pm 2.3 \%$ in comparison to free AZA $63 \pm 4.4 \%$ at a drug equivalent concentration at $36 \mathrm{~h}$. The dose $30 \mu \mathrm{M}$ of AZA-LIPO showed a significant increase $(p<0.05)$ in cytotoxicity in comparison to free AZA. Results revealed that particle size less than $200 \mathrm{~nm}$ and controlled release of optimized formulation are efficient in killing the cancer cells. The higher cell uptake/permeability of AZA-LIPO in cancer cells also enhanced the formulation cytotoxicity. Our results were well in agreement with the reported literature where Kashyap and co-worker have found similar results using PLGA as a nanocarrier [2].

\subsection{Confocal Microscopy}

The cellular uptake study was conducted to determine the cellular internalization of AZA-LIPO in MCF-7 cell. Due to negative $\log p$ value of AZA, it reduces the cellular uptake in cancer cells. FITC used which mimics as AZA in FITC-LIPO to evaluate the uptake of AZA in cells. FITC-LIPO treated cells exhibited green color FITC fluorescence in the cytoplasm of cells. Nano-sized AZA-LIPO showed comparatively slightly better 
cell uptake and enhanced cytotoxicity in MCF-7 cells (Figure 9C). Our results were in accordance with the recent report of Kashyap et al., 2020 where they used same drug but using different carrier i.e., PLGA nanoparticle [2].

\subsection{Effect of the AZA LPO on the Expression of Bax, Bcl-2 and Caspase-3 Proteins}

Higher Bcl-2 expression increases antiapoptotic activity, while Bax and caspase-3 expression induces apoptosis [50] (Figure 10A). AZA-LPO treatment produced a marked decrease in Bcl-2 expression relative to control and free AZA. On the other hand, treatment with AZA-LPO produced a significant $(p<0.05)$ increase in the expression of Bax $(260 \pm$ $15.79 \mathrm{pg} / \mathrm{mL}$ ) compared with free AZA (126.7 $\pm 11.13 \mathrm{pg} / \mathrm{mL}$ ) (Figure 10B). Caspase-3 activity is associated with cancer cell apoptosis [55,56]. Treatment with AZA-LPO $(44.68$ $\pm 2.45)$ produced a significant $(p<0.05)$ increase in caspase-3 activity compared to free AZA (28.89) (Figure 10C). Increased liposome efficacy relative to free AZA may be due to improved targeting at the cancer site. Another potential cause may be the improved absorption and internalization of AZA-LPO relative to free AZA in breast cancer cells. $[49,55,56]$.
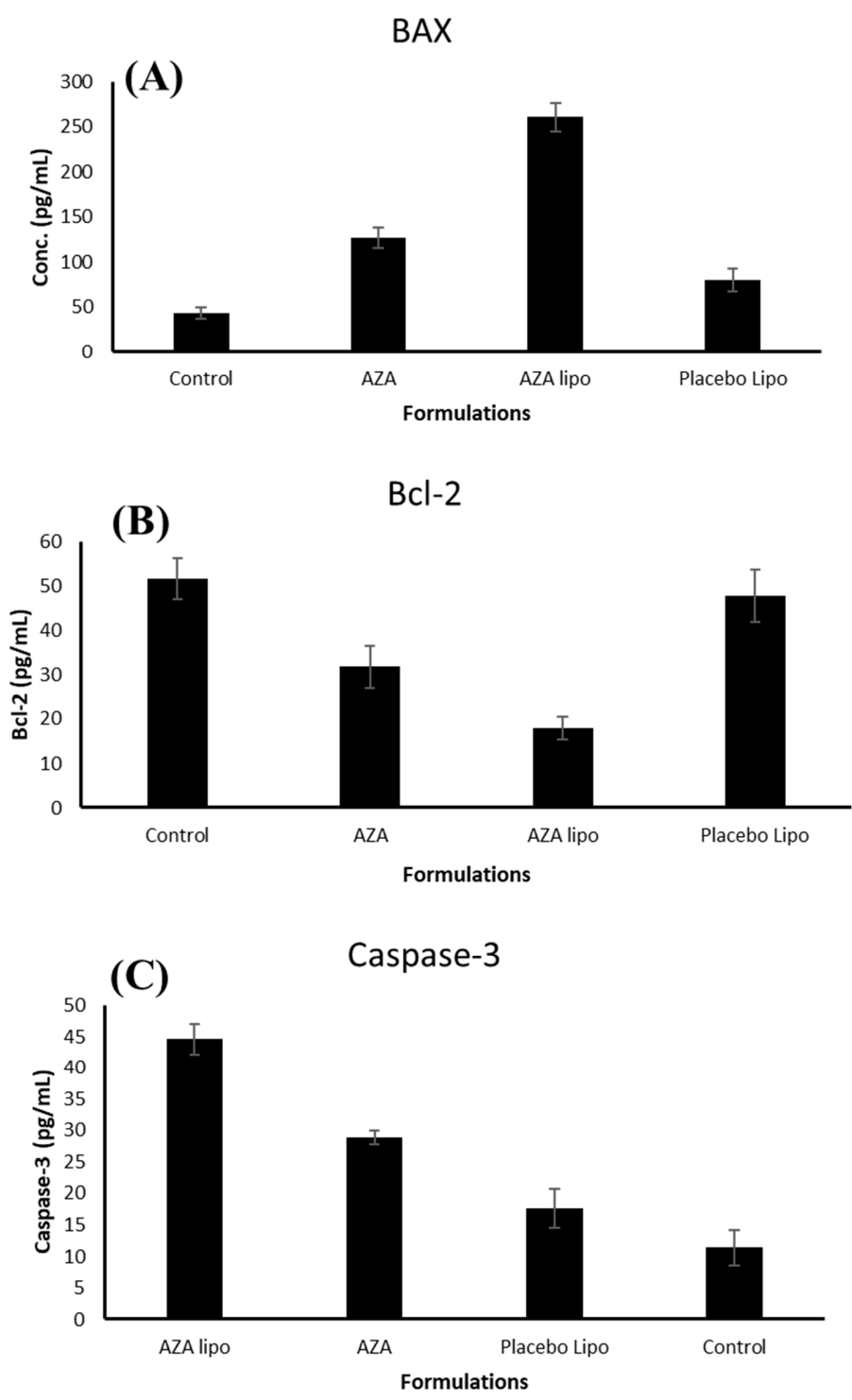

Figure 10. Effect of the IC50 concentrations of fee AZA, placebo liposomes and AZA-Lipo on the expression of Bax, Bcl-2 protein and caspase-3 activity in A549 cancer cells $(p<0.05$ for free AZA vs. AZA Lipo formulation. 


\section{Conclusions}

In the present research, AZA-LIPO formulations were developed and optimized using BBD and anticancer potentials were evaluated in MCF-7 breast cancer cells. The AZA-LIPO was prepared by a lipid thin film hydration technique. The selected CPPs were $w / v$ lipid concentration $\left(\mathrm{Y}_{1}\right)$, w/v cholesterol concentration $\left(\mathrm{Y}_{2}\right)$ and sonication time $(\mathrm{min})\left(\mathrm{Y}_{3}\right)$ with their respective levels -1 low, 0 medium, +1 high, whereas the dependent variables were particle size (nm) and \% drug entrapment efficiency (\%). The predicted independent variable was used to prepare formulation in a lab experimentally and predicted values of software for response were found to be very close to the experimental values i.e., predicted value was $110 \mathrm{~nm}$ and observed value was $107 \mathrm{~nm}$; similarly, EE\% was observed to be $85.2 \%$ in comparison to predicted $81.32 \%$. The optimized AZA-LIPO formulation showed an acceptable particle size, homogenous size distribution, spherical shape, high entrapment efficiency and controlled drug release profile. The MTT cytotoxicity assay on MCF-7 cell line revealed AZA-LIPO was more cytotoxic compared to free AZA. Further, confocal microscopy results proved higher cellular uptake of AZA-LIPO than plain AZA in cells. The AZA-LIPO was more effective than free AZA in increasing caspase- 3 and the proapoptotic Bax protein, while reducing the expression of the Bcl2 protein. Therefore, it can be concluded that proposed drug delivery system offers great prospects for anticancer therapy in future for breast cancer, only after establishing it with proper preclinical and clinical studies.

Author Contributions: Conceptualization, P.K.; Methodology, P.K. and S.M. and A.H.; Software and Formal Analysis, K.M.H., A.H.; Investigation, P.K., S.M.; Resources, P.K. and S.M.; Data Curation, P.K., N.A.A., A.H.; Writing—Original Draft Preparation, N.A.A., P.K. and K.M.H.; Writing-Review and Editing, P.K., N.A.A., A.H., and K.M.H.; Project Administration, P.K. and S.M.; Funding Acquisition, S.M., N.A.A. and P.K. All authors have read and agreed to the published version of the manuscript.

Funding: The deanship of Scientific Research (DSR) at King Abdulaziz University, Jeddah, Saudi Arabia has funded this project, under grant no (FP-132-42).

Institutional Review Board Statement: Not Applicable.

Informed Consent Statement: Not Applicable.

Data Availability Statement: Not Applicable.

Acknowledgments: The deanship of Scientific Research (DSR) at King Abdulaziz University, Jed.

Conflicts of Interest: The author declares no conflict of Interest.

\section{References}

1. Neupane, Y.R.; Srivastava, M.; Ahmad, N.; Kumar, N.; Bhatnagar, A.; Kohli, K. Lipid based nanocarrier system for the potential oral delivery of decitabine: Formulation design, characterization, ex vivo, and in vivo assessment. Int. J. Pharm. 2014, 477, 601-612. [CrossRef] [PubMed]

2. Kashyap, K.; Handa, M.; Shukla, R. Azacitidine Loaded PLGA Nanoparticles and their Dual Release Mechanism. Curr. Nanomed. 2020, 10, 280-289. [CrossRef]

3. Gore, S.D.; Jones, C.; Kirkpatrick, P. Decitabine. Nat. Rev. Drug Discov. 2006, 5, 891-892. [CrossRef] [PubMed]

4. Gkionis, L.; Campbell, R.A.; Aojula, H.; Harris, L.K.; Tirella, A. Manufacturing drug co-loaded liposomal formulations targeting breast cancer: Influence of preparative method on liposomes characteristics and in vitro toxicity. Int. J. Pharm. 2020, 590, 119926. [CrossRef] [PubMed]

5. Vakhshiteh, F.; Khabazian, E.; Atyabi, F.; Ostad, S.N.; Madjd, Z.; Dinarvand, R. Peptide-conjugated liposomes for targeted miR-34a delivery to suppress breast cancer and cancer stem-like population. J. Drug Deliv. Sci. Technol. 2020, 57, 101687. [CrossRef]

6. Briot, T.; Roger, E.; Lautram, N.; Verger, A.; Clavreul, A.; Lagarce, F. Development and in vitro evaluations of new decitabine nanocarriers for the treatment of acute myeloid leukemia. Int. J. Nanomed. 2017, 12, 8427-8442. [CrossRef]

7. Stresemann, C.; Lyko, F. Modes of action of the DNA methyltransferase inhibitors azacytidine and decitabine. Int. J. Cancer 2008, 123, 8-13. [CrossRef]

8. Momparler, R.L. Pharmacology of 5-aza-2'-deoxycytidine (decitabine). Semin. Hematol. 2005, 42. [CrossRef]

9. Hirnle, P. Liposomes for drug targeting in the lymphatic system. Hybridoma 1997, 16, 127-132. [CrossRef]

10. Jain, A.; Jain, K.; Kesharwani, P.; Jain, N.K. Low density lipoproteins mediated nanoplatforms for cancer targeting. J. Nanopart. Res. 2013, 15, 1888. [CrossRef] 
11. Ağardan, N.B.M.; Değim, Z.; Yılmaz, Ş.; Altıntaş, L.; Topal, T. Tamoxifen/raloxifene loaded liposomes for oral treatment of breast cancer. J. Drug Deliv. Sci. Technol. 2020, 57, 101612. [CrossRef]

12. Swami, R.; Kumar, Y.; Chaudhari, D.; Katiyar, S.S.; Kuche, K.; Katare, P.B.; Banerjee, S.K.; Jain, S. pH sensitive liposomes assisted specific and improved breast cancer therapy using co-delivery of SIRT1 shRNA and Docetaxel. Mater. Sci. Eng. C 2020, 111664. [CrossRef]

13. Tang, B.; Peng, Y.; Yue, Q.; Pu, Y.; Li, R.; Zhao, Y.; Hai, L.; Guo, L.; Wu, Y. Design, preparation and evaluation of different branched biotin modified liposomes for targeting breast cancer. Eur. J. Med. Chem. 2020, 193, 112204. [CrossRef] [PubMed]

14. Feuser, P.E.; Cordeiro, A.P.; de Bem Silveira, G.; Borges Corrêa, M.E.A.; Lock Silveira, P.C.; Sayer, C.; de Araújo, P.H.H.; Machadode-Ávila, R.A.; Dal Bó, A.G. Co-encapsulation of sodium diethyldithiocarbamate (DETC) and zinc phthalocyanine (ZnPc) in liposomes promotes increases phototoxic activity against (MDA-MB 231) human breast cancer cells. Colloids Surf. B Biointerfaces 2021, 197, 111434. [CrossRef]

15. Ahmed, K.S.; Hussein, S.A.; Ali, A.H.; Korma, S.A.; Lipeng, Q.; Jinghua, C. Liposome: Composition, characterisation, preparation, and recent innovation in clinical applications. J. Drug Target. 2019, 27, 742-761. [CrossRef]

16. $\mathrm{Xu}, \mathrm{X}$.; Khan, M.A.; Burgess, D.J. A quality by design (QbD) case study on liposomes containing hydrophilic API: I. Formulation, processing design and risk assessment. Int. J. Pharm. 2011, 419, 52-59. [CrossRef]

17. Sylvester, B.; Porfire, A.; Muntean, D.M.; Vlase, L.; Luput, L.; Licarete, E.; Sesarman, A.; Alupei, M.C.; Banciu, M.; Achim, M.; et al. Optimization of prednisolone-loaded long-circulating liposomes via application of Quality by Design (QbD) approach. J. Liposome Res. 2018, 28, 49-61. [CrossRef]

18. Shi, J.; Ma, F.; Wang, X.; Wang, F.; Liao, H. Formulation of liposomes gels of paeonol for transdermal drug delivery by Box-Behnken statistical design. J. Liposome Res. 2012, 22, 270-278. [CrossRef]

19. Rane, S.; Prabhakar, B. Optimization of paclitaxel containing pH-sensitive liposomes by 3 factor, 3 level box-behnken design. Indian J. Pharm. Sci. 2013, 75, 420-426. [CrossRef]

20. Patel, R.P.; Patel, H.; Baria, A.H. Formulation and Evaluation of Liposomes of Ketoconazole. Int. J. Drug Deliv. Technol. 2009, 1, 16-23. [CrossRef]

21. Muppidi, K.; Pumerantz, A.S.; Wang, J.; Betageri, G. Development and Stability Studies of Novel Liposomal Vancomycin Formulations. ISRN Pharm. 2012, 2012, 636743. [CrossRef] [PubMed]

22. Alexopoulou, E.; Georgopoulos, A.; Kagkadis, K.A.; Demetzos, C. Preparation and characterization of lyophilized liposomes with incorporated quercetin. J. Liposome Res. 2006, 16, 17-25. [CrossRef] [PubMed]

23. Ferreira, S.L.C.; Bruns, R.E.; Ferreira, H.S.; Matos, G.D.; David, J.M.; Brandão, G.C.; da Silva, E.G.P.; Portugal, L.A.; dos Reis, P.S.; Souza, A.S.; et al. Box-Behnken design: An alternative for the optimization of analytical methods. Anal. Chim. Chim. Acta 2007, 597, 179-186. [CrossRef] [PubMed]

24. Shah, V.H.; Jobanputra, A. Enhanced Ungual Permeation of Terbinafine HCl Delivered Through Liposome-Loaded Nail Lacquer Formulation Optimized by QbD Approach. AAPS PharmSciTech 2018, 19, 213-224. [CrossRef] [PubMed]

25. Shukla, P.; Gupta, G.; Singodia, D.; Shukla, R.; Verma, A.K.; Dwivedi, P.; Kansal, S.; Mishra, P.R. Emerging trend in nanoengineered polyelectrolyte-based surrogate carriers for delivery of bioactives. Expert Opin. Drug Deliv. 2010, 7, $993-1011$. [CrossRef]

26. Jain, P.; Tiwari, M.; Kumar, N.; Chonkar, A.; Rao, J.V.; Udupa, N. Oral administration of decitabine nanoparticles effectively suppresses Nmu-induced leukaemia in Sprague-Dawley rats and arrests K562 cells in S-phase. Int. J. Pharm. Clin. Res. 2016, $8,1260-1268$.

27. Kesharwani, P.; Banerjee, S.; Padhye, S.; Sarkar, F.H.; Iyer, A.K. Parenterally administrable nano-micelles of 3,4-difluorobenzylidene curcumin for treating pancreatic cancer. Colloids Surf. B Biointerfaces 2015, 132, 138-145. [CrossRef]

28. Wen, A.-H.; Choi, M.-K.; Kim, D.-D. Formulation of Liposome for topical delivery of arbutin. Arch. Pharm. Res. 2006, 29, 1187-1192. [CrossRef]

29. Gorain, B.; Choudhury, H.; Pandey, M.; Kesharwani, P. Paclitaxel loaded vitamin E-TPGS nanoparticles for cancer therapy. Mater. Sci. Eng. C 2018. [CrossRef]

30. Shukla, R.; Kumar, J.; Dwivedi, P.; Gatla, P.; Mishra, P.R. Microparticles of diethylcarbamazine citrate for the treatment of lymphatic filariasis. Asian J. Chem. 2013, 25, S302.

31. Kesharwani, P.; Tekade, R.K.; Gajbhiye, V.; Jain, K.; Jain, N.K. Cancer targeting potential of some ligand-anchored poly(propylene imine) dendrimers: A comparison. Nanomed. Nanotechnol. Biol. Med. 2011, 7, 295-304. [CrossRef] [PubMed]

32. Shukla, R.; Gupta, J.; Shukla, P.; Dwivedi, P.; Tripathi, P.; Bhattacharya, S.M.; Mishra, P.R. Chitosan coated alginate micro particles for the oral delivery of antifilarial drugs and combinations for intervention in Brugia malayi induced lymphatic filariasis. RSC Adv. 2015, 5, 69047-69056. [CrossRef]

33. Bunjes, H.; Unruh, T. Characterization of lipid nanoparticles by differential scanning calorimetry, $\mathrm{X}$-ray and neutron scattering Adv. Drug Deliv. Rev. 2007, 59, 379-402. [CrossRef] [PubMed]

34. Pardhi, V.P.; Verma, T.; Flora, S.J.S.; Chandasana, H.; Shukla, R. Nanocrystals: An Overview of Fabrication, Characterization and Therapeutic Applications in Drug Delivery. Curr. Pharm. Des. 2019, 24, 5129-5146. [CrossRef]

35. Pabst, G.; Rappolt, M.; Amenitsch, H.; Laggner, P. Structural information from multilamellar liposomes at full hydration: Full q-range fitting with high quality X-ray data. Phys. Rev. E Stat. Phys. Plasmas Fluids Relat. Interdiscip. Top. 2000, 62, 4000. [CrossRef]

36. De Jonge, N.; Ross, F.M. Electron microscopy of specimens in liquid. Nat. Nanotechnol. 2011, 6, 695-704. [CrossRef] 
37. Kesharwani, P.; Tekade, R.K.; Jain, N.K. Generation dependent safety and efficacy of folic acid conjugated dendrimer based anticancer drug formulations. Pharm. Res. 2015, 32, 1438-1450. [CrossRef]

38. Niu, G.; Cogburn, B.; Hughes, J. Preparation and characterization of doxorubicin liposomes. Methods Mol. Biol. 2010, 624, 211-219. [CrossRef]

39. Sun, W.; Zhang, N.; Li, A.; Zou, W.; Xu, W. Preparation and evaluation of N3-O-toluyl-fluorouracil-loaded liposomes. Int. J. Pharm. 2008, 353, 243-250. [CrossRef]

40. Kesharwani, P.; Tekade, R.K.; Jain, N.K. Formulation development and in vitro-in vivo assessment of the fourth-generation PPI dendrimer as a cancer-targeting vector. Nanomedicine 2014, 9, 2291-2308. [CrossRef]

41. Kesharwani, P.; Tekade, R.K.; Jain, N.K. Generation dependent cancer targeting potential of poly(propyleneimine) dendrimer. Biomaterials 2014, 35, 5539-5548. [CrossRef] [PubMed]

42. Devi, L.; Gupta, R.; Jain, S.K.; Singh, S.; Kesharwani, P. Synthesis, characterization and in vitro assessment of colloidal gold nanoparticles of Gemcitabine with natural polysaccharides for treatment of breast cancer. J. Drug Del. Sci. Technol. 2020, 56A, 101565. [CrossRef]

43. Kesharwani, P.; Mishra, V.; Jain, N.K. Generation dependent hemolytic profile of folate engineered poly(propyleneimine) dendrimer. J. Drug Deliv. Sci. Technol. 2015, 28, 1-6. [CrossRef]

44. Singh, A.; Vaishagya, K.; Verma, R.K.; Shukla, R. Temperature/pH-Triggered PNIPAM-Based Smart Nanogel System Loaded With Anastrozole Delivery for Application in Cancer Chemotherapy. AAPS PharmSciTech 2019, 20, 213. [CrossRef] [PubMed]

45. Anitha, A.; Deepagan, V.G.; Divya Rani, V.V.; Menon, D.; Nair, S.V.; Jayakumar, R. Preparation, characterization, in vitro drug release and biological studies of curcumin loaded dextran sulphate-chitosan nanoparticles. Carbohydr. Polym. 2011, 84, 1158-1164. [CrossRef]

46. Kesharwani, P.; Gajbhiye, V.; Tekade, R.K.; Jain, N.K. Evaluation of dendrimer safety and efficacy through cell line studies. Curr. Drug Targets 2011, 12, 1478-1497. [CrossRef]

47. Li, S.Y.; Sun, R.; Wang, H.X.; Shen, S.; Liu, Y.; Du, X.J.; Zhu, Y.H.; Jun, W. Combination therapy with epigenetic-targeted and chemotherapeutic drugs delivered by nanoparticles to enhance the chemotherapy response and overcome resistance by breast cancer stem cells. J. Control. Release 2015, 205, 7-14. [CrossRef]

48. Chawla, J.S.; Amiji, M.M. Cellular uptake and concentrations of tamoxifen upon administration in poly(E-caprolactone) nanoparticles. AAPS PharmSci 2003, 5, 28-34. [CrossRef]

49. Md, S.; Alhakamy, N.A.; Aldawsari, H.M.; Husain, M.; Kotta, S.; Abdullah, S.T.; Fahmy, U.A.; Alfaleh, M.A.; Asfour, H.Z. Formulation design, statistical optimization, and in vitro evaluation of a naringenin nanoemulsion to enhance apoptotic activity in a549 lung cancer cells. Pharmaceuticals 2020, 13, 152. [CrossRef]

50. Aldawsari, H.M.; Alhakamy, N.A.; Padder, R.; Husain, M.; Md, S. Preparation and characterization of chitosan coated plga nanoparticles of resveratrol: Improved stability, antioxidant and apoptotic activities in H1299 lung cancer cells. Coatings 2020, 10, 439. [CrossRef]

51. Park, Y.I.; Kwon, S.-H.; Lee, G.; Motoyama, K.; Kim, M.W.; Lin, M.; Niidome, T.; Choi, J.H.; Lee, R. pH-sensitive multi-drug liposomes targeting folate receptor $\beta$ for efficient treatment of non-small cell lung cancer. J. Control. Release 2021, $330,1-14$. [CrossRef] [PubMed]

52. Song, M.; Liang, Y.; Li, K.; Zhang, J.; Zhang, N.; Tian, B.; Han, J. Hyaluronic acid modified liposomes for targeted delivery of doxorubicin and paclitaxel to CD44 overexpressing tumor cells with improved dual-drugs synergistic effect. J. Drug Deliv. Sci. Technol. 2019, 53, 101179. [CrossRef]

53. Yu, Y.; Zu, C.; He, D.; Li, Y.; Chen, Q.; Chen, Q.; Wang, H.; Wang, R.; Chaurasiya, B.; Zaro, J.L.; et al. pH-dependent reversibly activatable cell-penetrating peptides improve the antitumor effect of artemisinin-loaded liposomes. J. Colloid Interface Sci. 2020, 586, 391-403. [CrossRef] [PubMed]

54. Zhao, Y.; Cai, F.; Shen, X.; Su, H. A high stable pH-temperature dual-sensitive liposome for tuning anticancer drug release. Synth. Syst. Biotechnol. 2020, 5, 103-110. [CrossRef]

55. Naseri, M.H.; Mahdavi, M.; Davoodi, J.; Tackallou, H.S.; Goudarzvand, M.; Neishabouri, S.H. Up regulation of Bax and down regulation of $\mathrm{Bcl} 2$ during 3-NC mediated apoptosis in human cancer cells. Cancer Cell Int. 2015, 15, 55. [CrossRef]

56. Sharifi, S.; Barar, J.; Hejazi, M.S.; Samadi, N. Doxorubicin changes Bax /Bcl-xL ratio, caspase-8 and 9 in breast cancer cells. Adv. Pharm. Bull. 2015, 5, 351-359. [CrossRef] 